\title{
ГАММА-ЛОКАТОР ДЛЯ РАДИОНУКЛИДНОЙ ДИАГНОСТИКИ ОНКОЛОГИЧЕСКИХ ЗАБОЛЕВАНИЙ
}

\author{
Ягнюкова А.К., Болоздыня А.И., \\ Канцеров В.А., Сосновцев В.В. \\ Национальный исследовательский ядерный университет «МИФИ», \\ Москва, Россия, \\ yagn.anastasia@gmail.com
}

Гамма-локатор - это миниатюрный детектор гамма-излучения на основе сцинтилляционного кристалла $\mathrm{LaBr}_{3}: \mathrm{Ce}$ и кремниевого фотоумножителя, предназначенный для использования в ядерной медицине с целью определения в режиме реального времени пространственного распределения радиоактивных фармацевтических препаратов в теле человека.
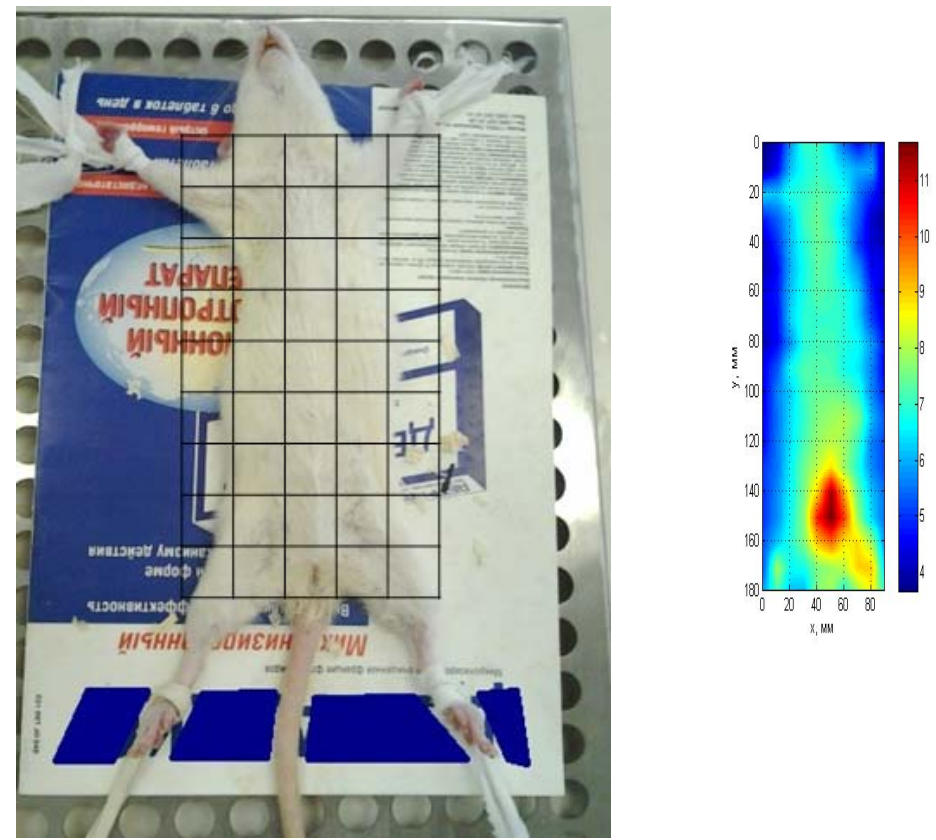

Рис.1. Восстановленное изображение распределения накопления РФП в животном 
Существуют две основные области применения гамма-локатора: интраоперационный поиск «сторожевых» лимфатических узлов и неинвазивное сканирование поверхности тела пациента. В первом случае радиофармпрепарат перед операцией вводят в тело пациента, и хирург во время удаления опухоли проверяет лимфатические узлы на наличие метастаз. Во втором случае с помощью гамма-локатора обнаруживают опухоли, расположенные поверхностно, и определяют их границы с высокой точностью.

Выбор кремниевого фотоумножителя (SiPM) в качестве фотоприемника гамма-локатора обусловлен его высокой эффективностью регистрации, небольшим напряжением смещения, компактными размерами и высоким коэффициентом усиления. Экспериментальные исследования показали, что сцинтиллятор $\mathrm{LaBr}_{3}: \mathrm{Ce}$, упакованный совместно с SiPM в непрозрачную герметичную сборку, обеспечивает энергетическое разрешение $6,9 \%$ на линии 662 кэВ.

Гамма-локатор оснащен разъемом USB для передачи данных на персональный компьютер, однако предусмотрен режим автономной работы при использовании литий-ионного аккумулятора. Индикация данных производится при помощи акустического сигнала и цифрового дисплея.

Измерены основные технические характеристики гамма-локатора с использованием источника гамма-излучения Со-57 (126 кэВ, 133 кэВ). Пространственное разрешение - минимальное расстояние между двумя точечными источниками гамма-квантов, излучение которых может быть проанализировано по отдельности - составило 8 мм. Угловое разрешение составило 26 градусов. Чувствительность прибора составила 12 имп $/ \mathrm{c} /$ кБк.

Гамма-локатор был испытан в режиме визуализации in vivo на лабораторной крысе, которой был введен радиофармпрепарат “Технефит”. Спустя три часа после введения радиофармпрепарат накопился преимущественно в мочевом пузыре, размеры которого составляют примерно 1 см, что позволило испытать прибор в условиях, близких к реальным условиям применения. 